\title{
Patients with anorectal malformation and upper limb anomalies: genetic evaluation is warranted
}

\author{
Desiree van den Hondel ${ }^{1}$ - Charlotte H. W. Wijers ${ }^{2}$ - Yolande van Bever ${ }^{3}$. \\ Annelies de Klein $^{3}$ - Carlo L. M. Marcelis ${ }^{4}$ - Ivo de Blaauw ${ }^{1,5}$. \\ Cornelius E. J. Sloots ${ }^{1} \cdot$ Hanneke IJsselstijn ${ }^{1}$
}

Received: 8 March 2015 /Revised: 16 September 2015 / Accepted: 7 October 2015 / Published online: 24 October 2015

(C) The Author(s) 2015. This article is published with open access at Springerlink.com

\begin{abstract}
The objective of this study was to compare the prevalence of genetic disorders in anorectal malformation (ARM) patients with upper limb anomalies to that in ARM patients with other associated anomalies. A retrospective case study was performed in two pediatric surgery centers. All patients born between 1990 and 2012 were included. VACTERL (vertebral defects (V), anal atresia (A), cardiac malformations (C), tracheoesophageal fistula with esophageal atresia (TE), renal dysplasia (R), and limb anomalies (L)) was defined as at least three
\end{abstract}

Communicated by Jaan Toelen

Revisions received: 07 July 2015; 17 September 2015

Electronic supplementary material The online version of this article (doi:10.1007/s00431-015-2655-9) contains supplementary material, which is available to authorized users.

Hanneke IJsselstijn

h.ijsselstijn@erasmusmc.nl

Desiree van den Hondel

d.vandenhondel@erasmusmc.nl

Charlotte H. W. Wijers

Lotte.Wijers@radboudumc.nl

Yolande van Bever

y.vanbever@erasmusmc.nl

Annelies de Klein

a.deklein@erasmusmc.nl

Carlo L. M. Marcelis

Carlo.Marcelis@radboudumc.nl

Ivo de Blaauw

Ivo.deBlaauw@radboudumc.nl components present. We included 700 ARM patients: 219 patients $(31 \%)$ had isolated ARM, 43 patients (6\%) had a major upper limb anomaly, and 438 patients $(63 \%)$ had other associated anomalies. The most prevalent upper limb anomalies were radial dysplasia $(n=12)$ and hypoplastic thumb $(n=11)$. Ten of the 43 patients $(23 \%)$ with an upper limb anomaly were diagnosed with a genetic disorder-nine also met the VACTERL criteria-vs. $9 \%$ of ARM patients with other anomalies ( $p=0.004$, chi-squared test).
Cornelius E. J. Sloots

c.sloots@erasmusmc.nl1

1 Department of Pediatric Surgery, Erasmus MC-Sophia Children's Hospital, Room SK-1280, P.O. Box 2060, 3000

CB Rotterdam, The Netherlands

2 Department for Health Evidence, Radboud University Medical Center, Nijmegen, The Netherlands

3 Department of Clinical Genetics, Erasmus MC, Rotterdam, The Netherlands

4 Department of Human Genetics, Radboud University Medical Center, Nijmegen, The Netherlands

5 Department of Surgery-Pediatric Surgery, Amalia Children's Hospital, Radboudumc, Nijmegen, The Netherlands 
Conclusion: Genetic disorders are twice as frequently diagnosed in ARM patients with upper limb anomalies than in those with other anomalies. As they also frequently meet the VACTERL criteria, it is important to consider VACTERL as a diagnosis per exclusionem. Genetic counseling is certainly warranted in these patients.

\section{What is Known:}

- Anorectal malformations (ARMs) often co-occur with other congenital anomalies, including upper limb anomalies, mainly of pre-axial origin.

- Co-occurrence of ARMs and upper limb anomalies is seen in disorders such as Townes-Brocks syndrome, Fanconi anemia, and VACTERL association.

What is New:

- ARM patients with a major upper limb anomaly - with or without other congenital anomalies - have a twofold greater chance of a genetic disorder than have non-isolated ARM patients without upper limb anomalies.

- Not all upper limb anomalies in ARM patients are part of the VACTERL association; a workup for genetic evaluation is proposed.

Keywords Anorectal malformation $\cdot$ Anorectal atresia . Upper extremity deformities, congenital · Syndrome .

VACTERL association

Abbreviations
ARM
CNS
MCA
syndrome
OMIM

Anorectal malformations

Central nervous system

Multiple congenital anomalies syndrome

OMIM, Online Mendelian Inheritance in

Man

VACTERL Vertebral defects (V), anal atresia (A), carassociation diac malformations $(\mathrm{C})$, tracheoesophageal fistula with esophageal atresia (TE), renal dysplasia (R), and limb anomalies (L)

\section{Introduction}

Anorectal malformations (ARMs) are rare congenital anomalies that occur in approximately 1 to 3 in every 5000 live births [13]. Of the ARM patients, 43 to $71 \%$ have additional congenital anatomical anomalies $[3,6,11,15,27]$. These include a great variety of upper limb anomalies, from a mild hypoplastic thumb to severe radial dysplasia $[7,10,11,18-20,26$, 29].

Some types of upper limb anomalies are associated with specific syndromes. For example, thumb anomalies may indicate Townes-Brocks syndrome, given the fact that $89 \%$ of the patients with Townes-Brocks syndrome have a thumb anomaly [16], or they may even indicate Fanconi anemia (prevalence of thumb anomalies $50 \%$ [28]). Ulnar deficiencies may be suggestive of, for example, ulnar-mammary syndrome [4]. Once evaluation has excluded known syndromes, VACTERL association can be considered, which refers to vertebral defects $(\mathrm{V})$, anal atresia $(A)$, cardiac malformations (C), tracheoesophageal fistula with esophageal atresia (TE), renal dysplasia (R), and limb anomalies (L). VACTERL association is mainly associated with preaxial limb defects [5].

Naturally, patients with more than one congenital anatomical anomaly are more likely to be diagnosed with a syndrome than are patients with a single congenital anomaly. However, in our experience, ARM patients with an upper limb anomaly - with or without other congenital anomalies - are more frequently diagnosed with a syndrome than are non-isolated ARM patients without upper limb anomalies. The aim of this study was to answer the following questions:

1. What is the prevalence of upper limb anomalies in ARM patients?

2. What upper limb anomalies are most frequently seen in ARM patients?

3. Are syndromes more prevalent in ARM patients with a major upper limb anomaly — with or without other additional congenital anomalies - compared to non-isolated ARM patients without an upper limb anomaly?

\section{Materials and methods}

\section{Study sample}

A retrospective case study was performed on all patients with an ARM born between 1 January 1990 and 1 July 2012 and treated in one of the participating university pediatric surgery centers (Erasmus MC-Sophia Children's Hospital, Rotterdam, the Netherlands, and Amalia Children's Hospital, Radboudumc, Nijmegen, the Netherlands). Patient characteristics were obtained from the medical records, with special attention to the presence of upper limb anomalies. This study was approved by the Erasmus MC Medical Ethical Review Board.

Two main groups were distinguished: isolated ARM patients and non-isolated ARM patients. The latter group was subdivided into patients with and without major upper limb anomalies (Fig. 1). The prevalence of genetic disorders was determined in these two subgroups.

\section{Classification systems}

ARMs were classified by the Krickenbeck classification [12]. VACTERL association was considered to be present if three or 


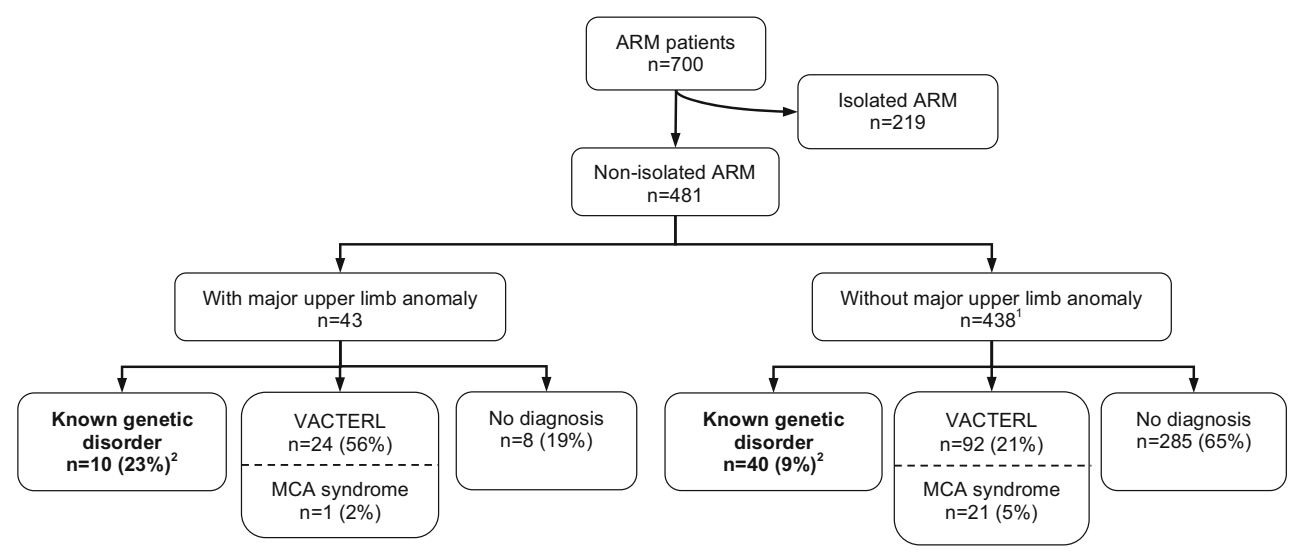

Fig. 1 Flow chart of patient selection. ARM anorectal malformations, $M C A$ syndrome multiple congenital anomalies syndrome. VACTERL was defined as three or more components present. Superscript number 1 , including 15 patients with a minor upper limb anomaly. As the minor anomalies, as classified by the clinical geneticists, are subjective

anomalies; these were not included in the main analysis. Superscript number 2 represents $p=0.004$, chi-squared test. Isolated ARM patients were excluded from analysis. The patients who had an upper limb anomaly were significantly more frequently diagnosed with a genetic disorder than those with other associated anomalies

more components of the acronym were identified [21, 25]. In our centers, all patients with ARM are screened for VACTERL association as follows: X-rays of the spine (V), echocardiogram of the heart (C), X-ray of the chest after insertion of a nasogastric tube (TE), ultrasound of the abdomen (R), and physical examination of the limbs (L).

Upper limb anomalies were classified as major or minor by the clinical geneticists (YB and CM). Examples of major anomalies are radial or ulnar dysplasia and polydactyly, and of minor anomalies are single palmar crease, long fingers, or long, coarse hands. As the minor anomalies are subjective anomalies, especially since this is a retrospective study, these were not included in the main analysis but mentioned separately.

Most major upper limb anomalies had been classified by the plastic surgeon as part of regular care (radial dysplasia and thumb hypoplasia were classified according to James et al. [14] and Abdel-Ghani et al. [1], respectively). Polydactyly was classified as preaxial or postaxial. Major upper limb anomalies in patients who had not been seen by the plastic surgeon were classified as type unknown $(n=4)$ and described according to the medical charts.

Patients with multiple congenital anomalies who had a pure clinical diagnosis, for which the underlying genetic defect is unknown, such as Goldenhar syndrome, were classified as "multiple congenital anomalies (MCA) syndrome" and not as "genetic disorder."

\section{Statistical analysis}

Results were shown as number (\%) or as median (range). Continuous variables were compared using the MannWhitney $U$ test, whereas proportions were compared using the chi-squared test.

The prevalence of genetic disorders was compared between ARM patients with a major upper limb anomaly - with or without other associated congenital anomalies - and nonisolated ARM patients without an upper limb anomaly. This was also done for organ systems, being lower limb, cardiac, central nervous system (CNS), urogenital, other gastrointestinal, and vertebral anomalies. Further, Phi analysis was conducted to determine whether anomalies in different organ systems were associated with each other.

\section{Results}

In total, 219 of the evaluated 700 patients ( $31 \%$ ) had an isolated ARM and were excluded from further analyses (Fig. 1). A major upper limb anomaly had been documented in 43 patients $(6 \%)$. Radial dysplasia was the most prevalent major upper limb anomaly $(n=12 ; 28 \%)$, followed by thumb hypoplasia $(n=11 ; 26 \%)$. Table 1 provides details of all major upper limb anomalies. Four patients were not classified by the plastic surgeon and were therefore classified as type unknown. The remaining 438 patients all had an ARM with other associated anomalies.

In 10/43 patients who had a major upper limb anomaly-with or without other congenital anomalies - a genetic disorder had been diagnosed (23\%; Table 2). Nine of these patients also met the criteria of VACTERL association. Of the remaining 33/43 patients, 24 had been diagnosed with VACTERL association per exclusionem (that is, $56 \%$ of patients with major upper limb anomaly) and one with Goldenhar syndrome; of the other eight patients, four had additional congenital anomalies but did not meet the VACTERL criteria and four had no other anomalies besides the ARM and upper limb anomaly. 
Table 1 Detailed findings in 43 anorectal malformation patients with a major upper limb anomaly

\begin{tabular}{|c|c|c|c|}
\hline & & Additional description & Disorder \\
\hline \multicolumn{4}{|c|}{ Radial dysplasia; $n=12$} \\
\hline \multirow[t]{2}{*}{ Type 0} & Unilateral & With thumb hypoplasia type 3 & VACTERL (trisomy X) \\
\hline & Bilateral & With thumb hypoplasia type 2 & 22q11 microduplication (maternal) \\
\hline \multirow[t]{3}{*}{ Type 2} & Unilateral & $\begin{array}{l}\text { With thumb hypoplasia type } 4 \text {; other hand radial } \\
\text { dysplasia type } 1 \text { with thumb hypoplasia type } 1\end{array}$ & Goldenhar syndrome \\
\hline & Unilateral & Unilateral radial dysplasia type 2 & $-{ }^{\mathrm{a}}$ \\
\hline & Bilateral & With thumb hypoplasia type 4 & VACTERL \\
\hline \multirow[t]{6}{*}{ Type 4} & Unilateral & With micromelia of 3 digits & VACTERL $^{\mathrm{b}}$ \\
\hline & Unilateral & $\begin{array}{l}\text { With thumb hypoplasia type } 5 \text { and syndactyly } 2 \text { nd and } \\
\text { 3rd digit; other hand thumb hypoplasia type unknown }\end{array}$ & VACTERL $^{b}$ \\
\hline & Unilateral & Other hand radial dysplasia type 1 & VACTERL \\
\hline & Bilateral & Bilateral radial dysplasia type 4 & VACTERL \\
\hline & Bilateral & With thumb hypoplasia type 5 & VACTERL \\
\hline & Bilateral & $\begin{array}{l}\text { With thumb hypoplasia type } 5 \text {; syndactyly } 2 \text { nd and } 3 \text { rd } \\
\text { digit, hypoplasia } 2 \text { nd digit, camptodactyly all digits }\end{array}$ & Fanconi anemia (no mutation known) \\
\hline Type unknown & Bilateral & Bilateral radial dysplasia, type unknown & Trisomy $18^{\mathrm{b}}$ \\
\hline \multicolumn{4}{|c|}{ Thumb hypoplasia without apparent radius involvement; $n=11$} \\
\hline \multirow[t]{4}{*}{ Type 2} & Unilateral & Unilateral thumb hypoplasia type 2 & VACTERL $^{\mathrm{a}}$ \\
\hline & Unilateral & Unilateral thumb hypoplasia type 2 & VACTERL $^{\mathrm{c}}$ \\
\hline & Unilateral & Unilateral thumb hypoplasia type 2 & VACTERL \\
\hline & Unilateral & Other hand thumb hypoplasia type 1 & VACTERL \\
\hline \multirow[t]{2}{*}{ Type 3} & Unilateral & Unilateral thumb hypoplasia type 3 & VACTERL $^{\mathrm{b}}$ \\
\hline & Bilateral & One hand triphalangeal thumb & VACTERL \\
\hline Type 4 & Bilateral & Bilateral thumb hypoplasia type 4 & VACTERL $^{\mathrm{b}}$ \\
\hline \multirow{2}{*}{ Type 5} & Unilateral & Other hand thumb hypoplasia type 2 & VACTERL \\
\hline & Unilateral & Other hand thumb hypoplasia type unknown & VACTERL $^{\mathrm{b}}$ \\
\hline \multirow[t]{2}{*}{ Type unknown } & Unilateral & Unilateral thumb hypoplasia type unknown & (16q12.1) polymorphism \\
\hline & Unilateral & Unilateral thumb hypoplasia type unknown & $-{ }^{\mathrm{a}}$ \\
\hline \multicolumn{4}{|c|}{ Ulnar dysplasia; $n=1$} \\
\hline & Unilateral & $\begin{array}{l}\text { Unilateral longitudinal ulnar growth arrest ( } 1 \text { thumb, } \\
3 \text { digits, floating } 4 \text { th digit). Other hand cleft hand } \\
\text { between } 4 \text { th and } 5 \text { th digit }\end{array}$ & $\begin{array}{l}\text { Ulnar-mammary syndrome, heterozygous } T B X 3 \\
\text { mutation (maternal) }\end{array}$ \\
\hline \multicolumn{4}{|c|}{ Preaxial polydactyly; $n=5$} \\
\hline & Unilateral & Extra thumb & VACTERL \\
\hline & Unilateral & Extra thumb & VACTERL \\
\hline & Bilateral & Extra thumb & a \\
\hline & Bilateral & Extra thumb & a \\
\hline & Bilateral & $\begin{array}{l}\text { One hand extra thumb, other hand } 7 \text { digits; both hands } \\
\text { syndactyly thumb and } 2 \text { nd digit and triphalangeal thumb }\end{array}$ & Townes-Brocks syndrome, $S A L L 1$ mutation \\
\hline \multicolumn{4}{|c|}{ Postaxial polydactyly; $n=2$} \\
\hline & Bilateral & 6 fingers; bilateral camptodactyly 2 nd -4 th digit & Trisomy $13^{\mathrm{b}}$ \\
\hline & Bilateral & Extra 6th metacarpal & $--^{\mathrm{a}}$ \\
\hline \multicolumn{4}{|c|}{ Thumb hyperplasia; $n=2$} \\
\hline & Unilateral & Same hand single palmar crease & VACTERL \\
\hline & Unilateral & Both hands also clasped thumb & VACTERL \\
\hline \multicolumn{4}{|l|}{ Other; $n=10$} \\
\hline & Unilateral & Triphalangeal thumb & Blackfan-Diamond anemia (no mutation known) \\
\hline & Bilateral & $\begin{array}{l}\text { Syndactyly 3rd-5th digit; other hand syndactyly } \\
\text { 3rd-4th digit }\end{array}$ & Trisomy 21 \\
\hline & Bilateral & $\begin{array}{l}\text { Syndactyly } 3 \text { rd }-5 \text { th digit; other hand absence of } 5 \text { th digit; } \\
\text { bilateral nail dysplasia }\end{array}$ & VACTERL $^{\mathrm{b}, \mathrm{d}}$ \\
\hline & Unilateral & Brachymesophalangy 5 th digit & $-^{\mathrm{a}}$ \\
\hline
\end{tabular}


Table 1 (continued)

\begin{tabular}{lll}
\hline & Additional description & Disorder \\
\hline Unilateral & Clasped thumb & $-^{\mathrm{a}}$ \\
Bilateral & Clasped hands & VACTERL $^{\mathrm{a}}$ \\
Unilateral & Deviating implantation of the thumb & VACTERL $^{\mathrm{a}}$ \\
Bilateral & Deviating implantation of the thumb & VACTERL \\
Unknown & Clino/brachydactyly not further specified & del $(1)(\mathrm{q} 23 \mathrm{q} 25)^{\mathrm{b}}$ \\
Bilateral & Clubbing hand, long fingers & Cri du Chat syndrome, der(5).t(5;14) \\
\hline
\end{tabular}

${ }^{\mathrm{a}}$ No known genetic disorder, does not meet criteria VACTERL association

${ }^{\mathrm{b}}$ Patient deceased

${ }^{\mathrm{c}} \mathrm{S} A L L-1$ mutation (Townes-Brocks syndrome) still needs to be excluded

${ }^{\mathrm{d}}$ GLI-3 mutation (Pallister Hall syndrome) still needs to be excluded

Forty of the 438 patients with other associated anomalies $(9 \%)$ had been diagnosed with a genetic disorder: 23 ( $5 \%$ of patients with non-isolated ARM without a major upper limb anomaly) with a numerical chromosomal disorder (mostly trisomy $21, n=17$; others were Turner syndrome and trisomy X) and $17(4 \%)$ with a microdeletion or duplication. Of these 40 patients, $14(35 \%)$ met the criteria for VACTERL association. Of the 398 remaining patients, 21 were diagnosed with an MCA syndrome and 92 patients met the criteria for VACTERL association.
The prevalence of genetic disorders (thus excluding VACTERL association and MCA syndromes) in the group of ARM patients with a major upper limb anomaly — with or without other anomalies - was significantly higher than that in the group of ARM patients with other associated anomalies: 23 vs. $9 \%$, respectively; $p=0.004$, chi-squared test.

The patient characteristics of the non-isolated ARM patients with and without major upper limb anomalies are shown in Table 3. The prevalence of urogenital anomalies did not

Table 2 Details of 10 patients with a major upper limb anomaly and a genetic disorder

\begin{tabular}{|c|c|c|}
\hline Genetic anomaly & Disorder (OMIM) & Associated anomalies \\
\hline \multicolumn{3}{|l|}{ Numerical chromosomal disorders } \\
\hline Trisomy $13^{\mathrm{a}}$ & Patau syndrome & $\begin{array}{l}\text { Typical dysmorphic features, possible esophageal atresia, ASD, } \\
\text { VSD, overriding aorta, absent external auditory canal, micropenis, } \\
\text { non-descended testes }\end{array}$ \\
\hline Trisomy $18^{\mathrm{a}}$ & Edward syndrome & Typical dysmorphic features, VSD, intrauterine growth retardation \\
\hline Trisomy 21 & Down syndrome & Typical dysmorphic features \\
\hline \multicolumn{3}{|l|}{ Microdeletions/duplications } \\
\hline 22q11 duplication & $\begin{array}{l}\text { 22q11 microduplication syndrome } \\
\text { (\#608363) }\end{array}$ & $\begin{array}{l}\text { Kidney agenesis, caudal regression syndrome, esophageal atresia, } \\
\text { VSD; mother had same duplication }\end{array}$ \\
\hline Heterozygous mutation $T B X 3$ & Ulnar-mammary syndrome (\#181450) & $\begin{array}{l}\text { Congenital subglottic stenosis, ASD, non-descended testes, mother } \\
\text { had same mutation }\end{array}$ \\
\hline SALL 1 mutation & Townes-Brocks syndrome (\#107480) & Bilateral dysplastic kidneys, hemivertebrae, club foot, hearing loss \\
\hline $\begin{array}{l}\text { Diagnosis confirmed by } \\
\text { hematologic investigations }\end{array}$ & Blackfan-Diamond anemia (\#105650) & VSD \\
\hline $\operatorname{del}(1)(\mathrm{q} 23 \mathrm{q} 25)^{\mathrm{a}}$ & No reference available & $\begin{array}{l}\text { Dysmorphic features, kidney agenesis, dextrocardia, esophageal } \\
\text { atresia, abnormal hearing }\end{array}$ \\
\hline $\begin{array}{l}\text { Diagnosis confirmed by } \\
\text { chromosomal breakage tests }\end{array}$ & Fanconi anemia & $\begin{array}{l}\text { Esophageal atresia, ADS, open ductus Botalli, hypospadia, hearing } \\
\text { loss, non-descended testes; familial }\end{array}$ \\
\hline $\operatorname{der}(5) \mathrm{t}(5 ; 14)^{\mathrm{a}}$ & Cri du Chat syndrome (\#123450) & $\begin{array}{l}\text { Dysmorphic features, VSD, bicuspid aortic valve, uterus didelphys, } \\
\text { enlarged kidney }\end{array}$ \\
\hline
\end{tabular}

OMIM, Online Mendelian Inheritance in Man, ASD atrial septal defect, VSD ventricular septal defect, AVSD atrioventricular septal defect

${ }^{a}$ Patient deceased. Due to treatment withdrawal, these patients were not all fully screened for other congenital anomalies

${ }^{\mathrm{b}}$ Parents did not consent for mutation analysis 
Table 3 Background characteristics of non-isolated anorectal malformation patients

\begin{tabular}{|c|c|c|}
\hline & $\begin{array}{l}\text { Non-isolated ARM with major } \\
\text { upper limb anomaly }\end{array}$ & $\begin{array}{l}\text { Non-isolated ARM without } \\
\text { upper limb anomaly }\end{array}$ \\
\hline Number of patients & $n=43$ & $n=438$ \\
\hline \multicolumn{3}{|l|}{ Type of ARM } \\
\hline Perineal fistula & $12(28 \%)$ & $139(32 \%)$ \\
\hline \multicolumn{3}{|l|}{ Rectourethral fistula } \\
\hline Bulbar & $2(5 \%)$ & $31(7 \%)$ \\
\hline Prostatic & $5(12 \%)$ & $46(11 \%)$ \\
\hline Unknown & $5(12 \%)$ & $38(9 \%)$ \\
\hline Rectovesical fistula & 0 & $15(3 \%)$ \\
\hline Vestibular fistula & $7(16 \%)$ & $62(14 \%)$ \\
\hline Cloaca & $3(7 \%)$ & $34(8 \%)$ \\
\hline Other & $2(5 \%)$ & $55(13 \%)$ \\
\hline Unknown & $7(16 \%)$ & $18(4 \%)$ \\
\hline Male sex & $22(51 \%)$ & $276(63 \%)$ \\
\hline Gestational age (weeks) & $38.5(29-43)$ & $38.0(26-42)$ \\
\hline Birth weight (g) & $2610(1020-3920)$ & $2980(625-4760)$ \\
\hline \multicolumn{3}{|l|}{ Associated anomalies $^{\mathrm{a}}$} \\
\hline Urogenital & $26(60 \%)$ & $272(62 \%)$ \\
\hline Cardiac & $26(60 \%)^{*}$ & $145(33 \%)^{*}$ \\
\hline Other skeletal $^{\mathrm{b}}$ & $20(47 \%)$ & $202(46 \%)$ \\
\hline Gastrointestinal & $19(44 \%)^{*}$ & $77(18 \%)^{*}$ \\
\hline Central nervous system & $8(19 \%)$ & $96(22 \%)$ \\
\hline Pulmonary & $4(9 \%)$ & $28(6 \%)$ \\
\hline
\end{tabular}

$A R M$ anorectal malformation

Results are presented as $n(\%)$ or as median (range)

${ }^{*} p<0.001$, chi-squared test

${ }^{a}$ Several patients had more than 1 associated anomaly

${ }^{\mathrm{b}}$ Skeletal anomalies other than upper limb anomalies differ between both groups (60 and $62 \%$ ), but cardiac anomalies (varying from atrial or ventricular septal defect to coarctation of the aorta or Fallot tetralogy) occurred more frequently in the patients with a major upper limb anomaly than those without (60 and $33 \%$, respectively; $p<0.001$ ). The same was true for gastrointestinal anomalies (44 vs. $18 \%$, respectively; $p<0.001)$. The most common gastrointestinal anomaly was esophageal atresia (with or without fistula), occurring in 13 patients of the major upper limb anomaly group (30\%). Others were duodenal atresia, small bowel atresia, and choledochal cyst.

We included 15 patients with a minor upper limb anomaly in the non-upper limb anomaly group. These minor anomalies were single palmar crease, long fingers, or large, coarse hands. Five of these patients ( $33 \%$ ) had been diagnosed with a genetic disorder: two patients had trisomy 21 , one had 47,XY,+ der(22) (Cat eye syndrome; OMIM \#607575), one had deletion 17p13.3 (Miller-Dieker syndrome; OMIM \#247200), and one had duplication of chromosome band 3p12.2 (no reference available).
The prevalence of genetic disorders in patients with associated anomalies other than upper limb anomalies is shown in Online Supplemental Table 4. The associations between the different associated anomalies were all poor (Online Supplemental Table 5).

\section{Discussion}

The prevalence of major upper limb anomalies in this cohort of $700 \mathrm{ARM}$ patients was $6 \%$. The most prevalent anomalies were radial dysplasia and thumb hypoplasia. Of the patients with a major upper limb anomaly, $23 \%$ had a genetic disorder versus $9 \%$ of other non-isolated ARM patients.

An extensive literature search yielded eight publications describing the prevalence of upper limb anomalies in ARM patients $[7,10,11,18-20,26,29]$. The prevalence ranged from 2 to $12 \%$ in study cohorts varying from 99 to 1417 ARM patients, which is in concurrence with the present study. However, none of these studies provided details of types of 


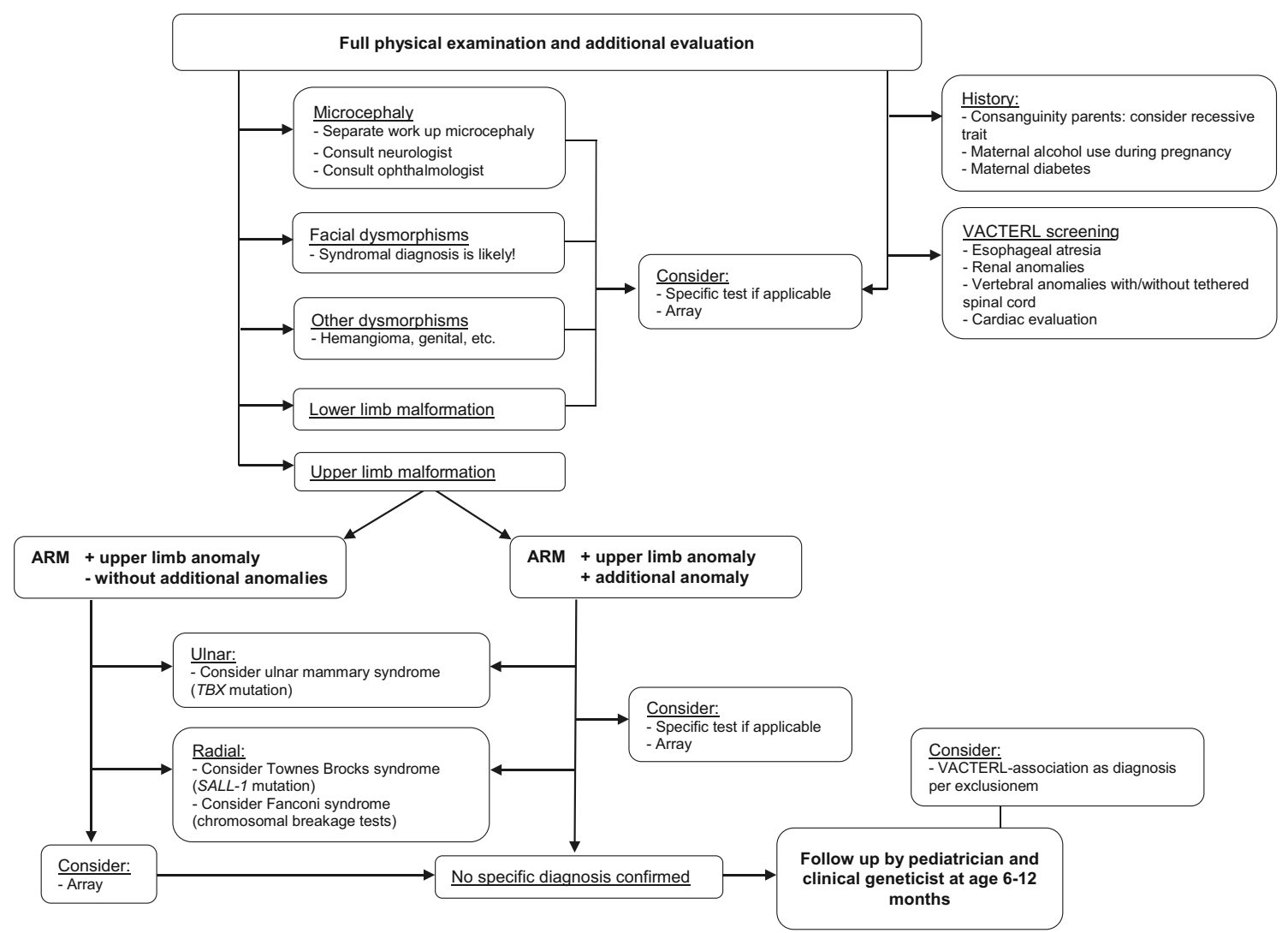

Fig. 2 Algorithm for workup of a patient with an anorectal malformation, with special attention to upper limb anomalies. ARM anorectal malformation. In this algorithm, which focuses on a workup for anorectal malformation patients with an upper limb anomaly, only the most relevant syndromes are mentioned. The purpose of this

anomalies or numbers of syndromes diagnosed in this patient group. In present study, we found that the most prevalent upper limb anomalies were radial dysplasia and thumb hypoplasia.

Unfortunately, because of the retrospective nature of this study, we were unable to determine at what ages the upper limb anomalies had been diagnosed. The prevalence of subtle upper limb anomalies such as thumb hypoplasia - in our study sample one of the most prevalent upper limb anomalies - could very well be underestimated in newborns. It might not only be because of the mere size of the hand and thumb but also when, for example, a plaster for a peripheral intravenous line covers the hand. Early recognition of the thumb anomaly is not only wanted for optimal treatment of the thumb $[1,17]$ but also even more for early recognition of syndromes such as Fanconi anemia. Even though Fanconi anemia is a rare disorder, the clinical consequences for the child warrant early recognition and this will also permit appropriate counseling of the parents. Unfortunately, we were unable to determine whether Fanconi syndrome had been excluded in all patients with radial limb deficiencies, but algorithm is to provide a general approach for pediatricians; it does not provide a complete genetic overview. This algorithm was designed based on current literature and experience of clinical geneticists, and on implementation of the findings of this study into clinical practice

chromosomal breakage tests were available in our country from the beginning of the study period.

Furthermore, the prevalence of other genetic diagnoses may have been underestimated because the possibilities for genetic testing have advanced rapidly since 1990 . In the 1990s, diagnostic investigations in medical genetics mostly consisted of karyotyping. In the Netherlands, TownesBrocks syndrome could be confirmed by Sanger sequencing from the late 1990s and 2005, respectively. Nowadays, the widespread application of affordable microarray approaches provides improved screening for genetic disorders [2]. In the Netherlands, clinical geneticists use arrays for screening since 2011. Further improvements in genetic diagnostics are to be expected with next-generation sequencing, where even smaller events can be detected and an absolute copy number prediction is possible $[2,23]$.

It is important to consider VACTERL association as a diagnosis per exclusionem and to have a keen eye for specific genetic disorders in this patient group, not only for the clinical consequences for the child but also to adequately counsel the parents in the case of an inheritable disorder. Ten of the 43 patients $(23 \%)$ with a major upper limb anomaly were 
diagnosed with a genetic disorder. This prevalence is higher than in patients without a major upper limb anomaly $(9 \%)$ and also higher than reported in patients with an upper limb anomaly without an ARM (7-17\%) [8, 9].

Besides the major upper limb anomalies, 15 patients had a minor upper limb anomaly, mostly large, coarse hands or deviating implant of the thumb. Compared to the major limb anomalies, a larger proportion of this group was diagnosed with a genetic disorder (33\%). This might be biased, as clinicians may tend to more actively search for small anomalies when a disorder is suspected based on dysmorphic features or a specific pattern of congenital anomalies, compared to the situation in which there is an isolated ARM without apparent associated anomalies. However, we recommend to consult a geneticist specialized in dysmorphology in all ARM patients, as these minor features can be hard to recognize while they still might hint towards a specific genetic disorder.

Cardiac and gastrointestinal anomalies were documented almost twice as much in patients with a major upper limb anomaly compared to other non-isolated ARM patients. Still, Phi analysis showed only poor associations between these anomalies and upper limb anomalies. These anomalies in part are inherent to the syndromes these patients were diagnosed with, but they can also be part of VACTERL association [22]. VACTERL screening in the neonatal period is internationally recommended for all ARM patients [24]. Preoperative cardiac screening by ultrasound should strongly be considered especially in ARM patients with an upper limb anomaly in order to minimize anesthesiologic risks.

This study provides new insights for the workup of a neonate with an ARM. When an upper limb anomaly is present, the pediatrician should be alert to genetic disorders. We propose an algorithm for genetic workup for ARM patients (Fig. 2). This algorithm includes the most relevant syndromes in order to provide a general approach. A clinical geneticist specialized in dysmorphology should be counseled when an ARM co-occurs with an upper limb anomaly, because of the great diversity of genetic disorders present in this patient group.

Concluding, the prevalence of major upper limb anomalies in ARM patients is $6 \%$. The most frequent anomalies were radial dysplasia and thumb hypoplasia. ARM patients with a major upper limb anomaly are twice as frequently diagnosed with a genetic disorder compared to ARM patients with other associated anomalies. Ninety percent of patients with a major upper limb anomaly and genetic disorder met the criteria for VACTERL association; it is therefore important to consider VACTERL association as a diagnosis per exclusionem and to be conscious of genetic disorders in patients with ARM and an upper limb anomaly. Consultations by a clinical geneticist specialized in dysmorphology in all ARM patients could help optimize screening for other syndromes.
Acknowledgments Gerdien de Jonge (librarian) helped conducting the literature search. Ko Hagoort provided editorial advice.

\section{Compliance with ethical standards}

Conflict of interest The authors declare that they have no competing interests.

Authors' contributions DH, YB, CEJS, and HIJ initiated and designed the study. DH, CHWW, YB, CLMM, and IB participated in data collection. $\mathrm{YB}$ and $\mathrm{AK}$ contributed to interpretation of the results. $\mathrm{DH}$ drafted the initial manuscript. All authors critically revised the paper and approved of the final manuscript as submitted. HIJ supervised the design and conduct of the research and monitored data analysis.

Open Access This article is distributed under the terms of the Creative Commons Attribution 4.0 International License (http://creativecommons.org/licenses/by/4.0/), which permits unrestricted use, distribution, and reproduction in any medium, provided you give appropriate credit to the original author(s) and the source, provide a link to the Creative Commons license, and indicate if changes were made.

\section{References}

1. Abdel-Ghani H, Amro S (2004) Characteristics of patients with hypoplastic thumb: a prospective study of 51 patients with the results of surgical treatment. J Pediatr Orthop B 13:127-138

2. Alkan C, Coe BP, Eichler EE (2011) Genome structural variation discovery and genotyping. Nat Rev Genet 12:363-376

3. Bălănescu RN, Topor L, Moga A (2013) Anomalies associated with anorectal malformations. Chirurgia (Bucur) 108:38-42

4. Bamshad M, Le T, Watkins WS, Dixon ME, Kramer BE, Roeder $\mathrm{AD}$ et al (1999) The spectrum of mutations in TBX3: genotype/ phenotype relationship in ulnar-mammary syndrome. Am J Hum Genet 64:1550-1562

5. Carli D, Garagnani L, Lando M, Fairplay T, Bernasconi S, Landi A et al (2014) VACTERL (vertebral defects, anal atresia, tracheoesophageal fistula with esophageal atresia, cardiac defects, renal and limb anomalies) association: disease spectrum in 25 patients ascertained for their upper limb involvement. J Pediatr 164: 458-462

6. Cho S, Moore SP, Fangman T (2001) One hundred and three consecutive patients with anorectal malformations and their associated anomalies. Arch Pediatr Adolesc Med 155:587-591

7. De Blaauw I, Wijers CHW, Schmiedeke E, Holland-Cunz S, Gamba P, Marcelis CL et al (2013) First results of a European multi-center registry of patients with anorectal malformations. J Pediatr Surg 48:2530-2535

8. Ekblom AG, Laurell T, Arner M (2010) Epidemiology of congenital upper limb anomalies in 562 children born in 1997 to 2007: a total population study from Stockholm, Sweden. J Hand Surg [Am] 35:1742-1754

9. Goldfarb CA, Wall LB, Bohn DC, Moen P, van Heest AE (2015) Epidemiology of congenital upper limb anomalies in a Midwest United States population: an assessment using the Oberg, Manske, and Tonkin classification. J Hand Surg [Am] 40:127-132

10. Gruchalski J, Irving IM, Lister J (1976) Skeletal anomalies associated with oesophageal, duodenal, and anorectal atresias. Lancet 1:517

11. Hassink EA, Rieu PN, Hamel BCJ, Severijnen RS, vd Staak FH, Festen C (1996) Additional congenital defects in anorectal malformations. Eur J Pediatr 155:477-482 
12. Holschneider A, Hutson J, Peña A, Beket E, Chatterjee S, Coran A et al (2005) Preliminary report on the international conference for the development of standards for the treatment of anorectal malformations. J Pediatr Surg 40:1521-1526

13. International Clearinghouse for Birth Defects Surveillance and Research. Annual report 2011: with data for 2009. Available at: www.icbdsr.org/filebank/documents/ar2005/Report2011.pdf. Accessed 2013 Dec 18

14. James MA, McCarroll HR Jr, Manske PR (1999) The spectrum of radial longitudinal deficiency: a modified classification. J Hand Surg [Am] 24:1145-1155

15. Julià V, Tarrado X, Prat J, Saura L, Montaner A, Castañón M et al (2010) Fifteen years of experience in the treatment of anorectal malformations. Pediatr Surg Int 26:145-149

16. Kohlhase J. Townes-Brocks syndrome (2007) In: Pagon RA, Adam MP, Bird TD, et al., eds. GeneReviews ${ }^{\mathrm{TM}}$ [Internet]. Seattle: University of Washington

17. Light TR, Gaffey JL (2010) Reconstruction of the hypoplastic thumb. J Hand Surg [Am] 35:474-479

18. Mittal A, Airon RK, Magu S, Rattan KN, Ratan SK (2004) Associated anomalies with anorectal malformation (ARM). Indian J Pediatr 71:509-514

19. Nah SA, Ong CC, Lakshmi NK, Yap TL, Jacobsen AS, Low Y (2012) Anomalies associated with anorectal malformations according to the Krickenbeck anatomic classification. J Pediatr Surg 47:2273-2278

20. Niedzielski J (2009) Congenital anomalies associated with ARM16-year experience of one surgeon. Arch Med Sci 5:596-601

21. Oral A, Caner I, Yigiter M, Kantarci M, Olgun H, Ceviz N et al (2012) Clinical characteristics of neonates with VACTERL association. Pediatr Int 54:361-364
22. Reutter H, Ludwig M (2013) VATER/VACTERL association: evidence for the role of genetic factors. Mol Syndromol 4: $16-19$

23. Solomon BD (2014) Obstacles and opportunities for the future of genomic medicine. Mol Genet Genomic Med 2:205-209

24. Solomon BD, Baker LA, Bear KA, Bk C, Giampietro PF, Hadigan $C$ et al (2014) An approach to the identification of anomalies and etiologies in neonates with identified or suspected VACTERL (vertebral defects, anal atresia, tracheoesophageal fistula with esophageal atresia, cardiac anomalies, renal anomalies, and limb anomalies) association. J Pediatr 164:451-457

25. Solomon BD, Bear KA, Kimonis V, de Klein A, Scot DA, ShawSmith C et al (2012) Clinical geneticists' views of VACTERL/ VATER association. Am J Med Genet A 158:3087-3100

26. Stoll C, Alembik Y, Dott B, Roth MP (2007) Associated malformations in patients with anorectal anomalies. Eur J Med Genet 50:281-290

27. Van den Hondel D, Sloots CE, Gischler SJ, Meeussen CJ, Wijnen RM (2013) Prospective long-term follow up of children with anorectal malformation: growth and development until 5 years of age. J Pediatr Surg 48:818-825

28. Webb ML, Rosen H, Taghinia A, McCarty ER, Cerrato F, Upton J et al (2011) Incidence of Fanconi anemia in children with congenital thumb anomalies referred for diepoxybutane testing. J Hand Surg [Am] 36:1052-1057

29. Wijers CHW, van Rooij IALM, Bakker MK, Marcelis CL, Addor MC, Barisic I et al (2013) Anorectal malformations and pregnancyrelated disorders: a registry-based case-control study in 17 European regions. BJOG 120:1066-1074 